Volume No.1, Issue No. 2, 2018 ISSN: 2616-9738 (Print) 2616-9746 (Online)

Journal DOI: https://doi.org/10.32350/uer Issue DOI: https://doi.org/10.32350/uer.12 Homepage: https://ssh.umt.edu.pk/uer/home.aspx

Journal QR Code:

Article:

Author(s):

Online Published: 2018

Article DOI:

\section{https://doi.org/10.32350/uer.12.01}

Article QR Code:

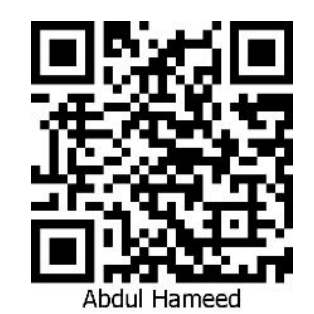

To cite this article: Hameed, A., \& Manzoor, A. (2018). A child on

Dr. Abdul Hameed
Dr. Afaf Manzoor
crossroad of two isolated worlds. UMT Education Review, 1(2), 02-18. $\underline{\text { Crossref }}$

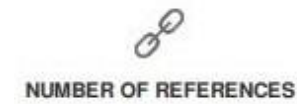

48

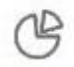

NUMBER OF FIGURES

02

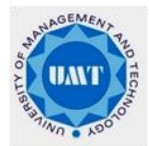

$\Xi \because$

NUMBER OF TABLES

02

A publication of the

Department of Education, School of Social Sciences and Humanities, University of Management and Technology, Lahore, Pakistan. 


\title{
A Child on Crossroad of Two Isolated Worlds
}

\author{
Dr. Abdul Hameed ${ }^{1}$ \\ Dr. Afaf Manzoor ${ }^{2}$
}

\begin{abstract}
An ever-increasing focus on out-of-school children may bring a new challenge to the already shaky system of schooling in Pakistan. A sustained segregatory and exclusionary way of thinking even at the highest ministerial level has given birth to two separate worlds; general education and special education. The habitat of both worlds follows different sets of beliefs about education, children, teaching and learning, pedagogy and assessment. The interaction between these communities has remained sorrowfully minimal. As the push to enroll every child in school with a target of "No child left behind" has increased, it has become even more difficult for parents and families to choose an appropriate school for children with disabilities. Often, the closest mainstream school treats them as aliens, whereas an alternative or special school may be up to $12 \mathrm{~km}$ away from the child leaving few or no option for parents to send their children with disabilities to school. As the Punjab government has taken a forward step for inclusive education in two districts, it has become more obvious that there are many challenges in creating realistic accommodations for children with special needs in "mainstream schools". This concept paper has explored the gaps both in theory and practice that may hinder the inclusion of all children in their neighborhood schools
\end{abstract}

Keywords: children with disabilities, inclusive education, out of school children, segregation, special education.

\section{Introduction}

Disability is associated with a higher risk of being out of school for children in developing countries. Mizunoya, Mitra and Yamasaki (2018) found that the disability gap in school attendance is consistent and statistically significant in 15 developing countries including Pakistan. Children with disabilities have 5.5 times higher chance to be out of school than children with no disabilities and in Pakistan, school is in complete access of about $4 \%$ of children with disabilities (Hameed, Manzoor \& Nabeel, 2018).

\footnotetext{
${ }^{1}$ Professor, University of Management and Technology, Lahore, Pakistan.

${ }^{2}$ Lecturer, University of Education, Lahore, Pakistan.

Corresponding Author: Dr. Abdul Hameed <drhameedpk@gmail.com>
} 
Student dropout rate is still rising and recent efforts of the government of Punjab's have exhausted still leaving 15 million children out of school (Alif Ailan, 2017). Serious attention is needed to address this issue, especially in context of children with some disability, since disability further minimizes the chances to attend school reducing the probability of school attendance by a median 30.9 percentage point (Mizunoya et al., 2018). Latif, Choudhary and Hammayun (2015) reported that only 50\% of children between 5 to 9 years attend school, but only $30 \%$ of those who attend the school complete their primary education (NCHD, 2010), whereas, students dropout ratio for girls is higher than boys (Mehmood, Chong \& Hussain, 2018).

Although internal and external pressure is attempting to encourage public and private institutions to respond in a meaningful manner, the percentage of out of school children remains unchanged. On the other hand, international standards suggested i.e. by UNICEF to measure the school participation rate at different ages or group levels have been fine-tuned to hold state parties accountable for the compliance of international treaties with improved transparency. As a result, every state across Pakistan is engaged in improving local measures to increase the participation rate. In all these efforts out of school child have become a focal point, but unfortunately, the diversified educational needs of all out of school children are not fully investigated and are yet unknown to policy makers and other stakeholders involved in better planning.

Out of school children are a critical issue in education and development throughout the world (Mizunoya et al., 2018). In order to include all out of schoolchildren in Punjab, the largest province of Pakistan, the School Education Department has recently begun the process of introducing the concept of 'inclusive education' in two large but educationally underdeveloped districts Bahawalpur and Muzaffargarh. For this purpose, screening and mapping of out of school children particularly with mild disabilities were undertaken to better understand their individual special education needs under a separate project "Punjab Inclusive Education Project". This is one of the first examples of collaboration between general and special education experts with the aim of ensuring all children can enroll in school.

As the Punjab government attempted to move toward inclusion, new educational realities have popped up highlighting the serious gaps in the way educators of public schools in Pakistan understand the purpose of contemporary education. Do people conducting mainstream education and special education render themselves same or different? The existence of 'The Two Cultures' seems somewhat similar as described in Snow's 1959 bestseller. In his book, Snow argued that the world of knowledge had divided itself into two isolated cultures; humanities and sciences and this split is the 
main hindrance in solving the contemporary problems. Similarly, in Pakistan as in other developing countries, special and, general education systems have emerged as two distinct cultures with an entirely different set of materials, methods, values, and traditions (Hameed, 2011). It appears that for educators and society in general, developing a mutual understanding of both cultures is taking more time. Fragmentation of these concepts at higher ministerial level has a ripple effect on education policy and practice. As a result, the education policies of past three decades in Pakistan do not even recognize children with disabilities as the most marginalized group as having a right to education (Hameed, 2012).

It is unfortunate that even with the substantial rebuilding of pre-service teacher education through US-funded Pre-STEP project Pakistan has failed to capitalize on the global movement of inclusive education and UN conventions such as Convention on the Rights of Persons with disabilities to meet the challenge of out of schoolchildren with disabilities (UNESCO, 2006). Hameed (2012) argues that due to fragmentation of education system in 'mainstream' and 'special', a new mindset has emerged that sees the education of a child in more clinical way based upon a medical model of disability (Triano, 2000); where diagnosis precedes the learning plan; inclusiveness becomes a hard target to achieve in this case. The child and the family has to undergo numerous trial before knowing whether or not a school exists to suit their needs.

\subsection{Family Struggle}

In Pakistan, the typical educational journey of a child with a disability starts from mother's feeling of something unusual with the child. She may take some time before sharing her concerns with her husband or others because of the stigma attached with a disability. It may take another three to six months to seek the help of family elders whose advice may be to take the child to a shrine spiritual healer. The family may then spend another three to six months in reaching the conclusion that "it is not working". They then contact a nearby medical doctor who in spite of knowing that the disability may be permanent, takes more time in completing pre-referral. By this time, may be between the ages of 1-2 years, which could have been the best time for early intervention known as the best option for children with different forms of disability (Bornstein, 2005; Guralnick, 1997). 


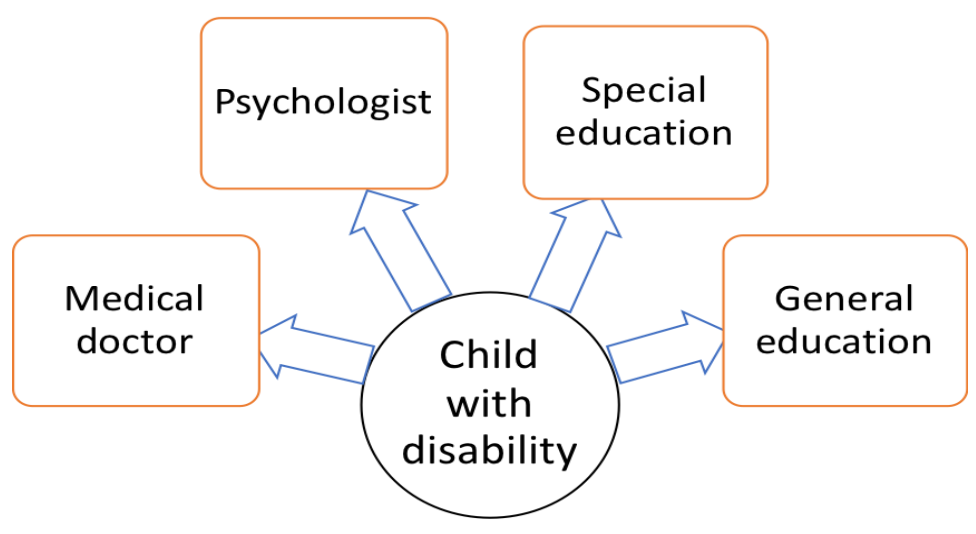

Figure 1: Parents Mapping for Caregivers

\subsection{The Diagnosis and the Irrelevant Primary School}

The child is lucky if he or she is brought to healthcare services for clinical investigation and diagnosis. Roughly speaking the percentage of these lucky children may not be more than 10 percent. The rest are brought up in extremely difficult circumstances defined by ignorance, neglect, and poverty. According to Croll and Moses (2000) schooling of special children becomes a Utopia; since those diagnosed eventually enter a special education school that is on average $12 \mathrm{~km}$ away from child's home in Pakistan. However, those who could not reach that far remain outside the walls of a special school, and are the most marginalized of all. Parents of these children who wish to send their children to neighboring general primary school unfortunately find that this school is not meant for their children (Manzoor, 2015). Hence, it is established that inclusion itself needs a special culture (Carrington, 1999; Miles \& Singal, 2010; Hameed et al., 2018). The school administration further strengthens this belief by refusing admission to all children with disabilities. In this way, the only hope to education diminishes silently. The major chunk (about 30\%) of out of school children is the result of this process of segregation and exclusion (Alif Ailan, 2017).

\subsection{The Causes of School Failure}

School behavior is not unexpected as the whole makeup of school curricula; pedagogy, instruction and assessment are kept disability-free at all levels. None of the pre-service and in-service teacher education programs in Pakistan as in other developing countries consider children with disabilities (Sharma \& Das, 2015). Moreover, the special education system serves as a scapegoat and provides relief to those only who have accepted their children as disabled but special. However, it would be naive to think that I feel my child is differently abled and I can get him/her admitted to nearby primary 
school. So how should parents deal with the education of their special children? Should they choose to make them more vulnerable by sending them to schools at a distance of 10 kilometers or sometimes more, or should the system allow their children to be admitted in nearby schools? It is not just an attitudinal problem of school heads and teachers as they hesitate showing a positive attitude toward these children; they might have 100 reasons, such as lack of proper infrastructure, complaints of parents of typically developing children (Haider, 2008). Whatever is true, the divide is deeper than it appears to be at the outset, and children with a disability cannot be easily accommodated in nearby primary schools in Pakistan (Sathar \& Lloyd, 1994).

\subsection{The Two Cultures}

The cultures of general and special education can be compared in many ways. However, in the present study the framework proposed by Bray and Thomas (1995) was applied suiting the needs of study as they have proposed a three-dimensional model including non-locational demographic groups, geographic/locational levels and aspects of education and of society. In the present study, the entire population forms the first dimension; the second dimension represents those schools in which some modifications were incorporated to make it inclusive; this way the framework could cover the common aspects of both general and special education systems. The adapted framework is graphically presented in figure 2 .

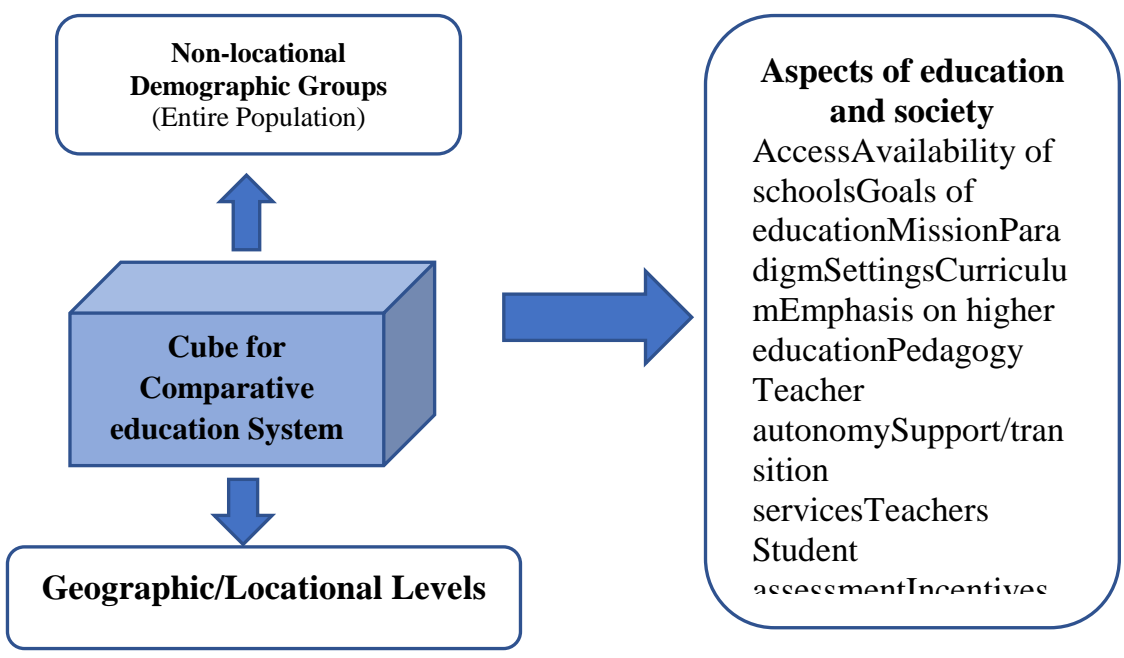

Figure 2: Framework for comparative education analysis adapted from Bray $\&$ Thomas (1995) Cube. 
Table 1

Comparison between Worlds of Special and General Education

\begin{tabular}{|c|c|c|}
\hline Aspect & General education & Special education \\
\hline Access & $\begin{array}{l}\text { Open to all "normal" children. } \\
\text { However, in private sectors, this } \\
\text { access is tied to affordability as } \\
\text { well }\end{array}$ & $\begin{array}{l}\text { Restricted to children with } \\
\text { disabilities except few i.e. } \\
\text { "normal", children with } \\
\text { autism, ADHD and multiple } \\
\text { disabilities }\end{array}$ \\
\hline $\begin{array}{l}\text { Availability } \\
\text { of school }\end{array}$ & $\begin{array}{l}\text { School is available within } 1 \mathrm{~km} \\
\text { distance in order to remove } \\
\text { distance penalty to incoming } \\
\text { children. Such provisions are } \\
\text { even lavishly available to both } \\
\text { genders in many villages. }\end{array}$ & $\begin{array}{l}\text { A special school is available } \\
\text { at } 12 \mathrm{~km} \text { away from the home } \\
\text { of a special child on average. } \\
\text { The children with disability } \\
\text { have to pay } 12 \text { times extra } \\
\text { distance penalty in addition to } \\
\text { the difficult circumstances due } \\
\text { to disabilities they already in. }\end{array}$ \\
\hline $\begin{array}{l}\text { Goal of } \\
\text { education }\end{array}$ & $\begin{array}{l}\text { To actualize the potential of } \\
\text { every child in order to prepare } \\
\text { her/ him for future challenges. } \\
\text { Provision ofquality higher/ } \\
\text { further education. }\end{array}$ & $\begin{array}{l}\text { Prepare the child for } \\
\text { independent living and low- } \\
\text { paid blue-collar jobs. Train to } \\
\text { work in a protected } \\
\text { environment with reduced job } \\
\text { requirements }\end{array}$ \\
\hline Mission & $\begin{array}{l}\text { Learning to lead in each walk of } \\
\text { social life }\end{array}$ & $\begin{array}{l}\text { Learning to function } \\
\text { independently }\end{array}$ \\
\hline Paradigm & $\begin{array}{l}\text { Industrial model for better } \\
\text { productivity under total quality } \\
\text { control }\end{array}$ & $\begin{array}{l}\text { Medical model to fix the } \\
\text { handicapping conditions under } \\
\text { a restricted environment }\end{array}$ \\
\hline Setting & Natural and open & $\begin{array}{l}\text { Clinical with restrictions and } \\
\text { individual care }\end{array}$ \\
\hline Curriculum & $\begin{array}{l}\text { Uniform, national, standardized, } \\
\text { and inflexible }\end{array}$ & Adapted, local, flexible \\
\hline $\begin{array}{l}\text { Emphasis } \\
\text { on higher } \\
\text { education }\end{array}$ & $\begin{array}{l}\text { Higher education in science, } \\
\text { medical and engineering. Strong } \\
\text { foundations in science and } \\
\text { mathematics are laid. }\end{array}$ & $\begin{array}{l}\text { Vocational education or arts } \\
\text { education is the height of } \\
\text { educational goals. Science and } \\
\text { mathematics education is not } \\
\text { desired even at the secondary } \\
\text { level. }\end{array}$ \\
\hline Pedagogy & $\begin{array}{l}\text { General, group teaching, } \\
\text { average learning demands, } \\
\text { centralized instructional plan }\end{array}$ & $\begin{array}{l}\text { Child-centered, individualized, } \\
\text { and individualized targets. No } \\
\text { accountability and no } \\
\text { centralized instructional plan }\end{array}$ \\
\hline
\end{tabular}




\begin{tabular}{|c|c|c|}
\hline & $\begin{array}{l}\text { with full accountability based on } \\
\text { student's assessment results }\end{array}$ & \\
\hline $\begin{array}{l}\text { Teacher } \\
\text { autonomy }\end{array}$ & $\begin{array}{l}\text { The teacher is paid functionary } \\
\text { and exercises zero control on } \\
\text { curriculum and instruction }\end{array}$ & $\begin{array}{l}\text { The teacher is trained to adapt } \\
\text { curriculum and instruction } \\
\text { according to diversified needs } \\
\text { students }\end{array}$ \\
\hline $\begin{array}{l}\text { Support/ } \\
\text { transition } \\
\text { services }\end{array}$ & $\begin{array}{l}\text { No concept of additional } \\
\text { support whatsoever }\end{array}$ & $\begin{array}{l}\text { Speech therapy, psychological } \\
\text { counseling, occupational } \\
\text { therapy, and other support staff }\end{array}$ \\
\hline Teachers & General pre-service training & $\begin{array}{l}\text { Intensive specialized training } \\
\text { to deal with disabilities }\end{array}$ \\
\hline $\begin{array}{l}\text { Students } \\
\text { assessment }\end{array}$ & $\begin{array}{l}\text { Uniform, standard achievement } \\
\text { tests, norm-based interpretation } \\
\text { of results }\end{array}$ & $\begin{array}{l}\text { Adapted, individualized, } \\
\text { flexible locally interpreted }\end{array}$ \\
\hline Incentive & $\begin{array}{l}\text { Cash award/ stipend to the girl } \\
\text { child }\end{array}$ & $\begin{array}{l}\text { Cash, free uniform, books, } \\
\text { transport, shoes }\end{array}$ \\
\hline
\end{tabular}

The comparison of the two systems discussed above clearly indicates that not only they are quite different from each other, but they are also deviating from the principles outlined in the Index of Inclusion (Booth \& Ainscow, 2002). The index for inclusion is the framework developed for schools and educational systems that examines the development of inclusion across three dimensions, culture, policy, and practices. Current study is not related to either an administrative or a policy issue but more likely stems from assimilated effect of beliefs, values and traditions of both cultures i.e. general education and special education and their related practices.

A closer look suggests that this fragmentation starts from the very beginning, i.e., goal setting for curriculum of each program. General education prepares youth to respond effectively to both predictable and unpredictable challenges the future holds for them. Efforts are made to develop metacognition instead of focusing on specific training in a particular trade. On the contrary, special education is built on assumptions and expectations of low achievement concerning of children with disabilities and is more focused on achieving the goal of independent living. As a result of such goals, there is often very little emphasis on science and mathematics education in special education (Hameed, 2005; Farooq, 2013).

Promoting inclusive education requires a lot of external effort to ensure access and positive learning outcomes for all children, including children with disabilities (Bakhshi, Babulal \& Jean-Francois, 2018). In Pakistan the rigor of curriculum content is frequently compromised in special education (Farooq, 2013). The popular method of curriculum adaptation is to use a textbook, which is written for the student who is two years behind and reduce the content on the premise that students with disabilities will not be able to carry an extra 
burden (Hameed \& Manzoor, 2014). As far as general education is concerned efforts are kept up to date with global development since benchmarking of the popular foreign curriculum is on the rise in Pakistan. According to Hameed et al (2018), sometimes even a complete set of international curricula is implanted without indigenizing or localizing it for the pursuit of international quality. High standards, total quality control, and stringent accountability define the culture of general education today. There is an ever-widening gap between quality standards in special and general education (Hameed \& Fazil, 2012).

Educational settings of both systems are markedly different. In special schools a restricted environment is maintained. Sometimes outdoors are locked not because of security reasons but to protect children from any bodily harm. On the other hand, general school functions in an open environment. A large number of primary schools are without boundary (Annual Status of Education Report [ASER], 2016). Students are free to read and play. This openness has a positive effect on the growth of young learners. Special schools are asked to provide a learning environment with least restriction but because of a pathological mindset controlled learning conditions are preferred.

The pedagogy of both systems is also based on different psychological foundations. In general education teachers are prepared to teach a class where students with similar educational needs are found (Sharma, Simi \& Forlin, 2015). The teachers are not exposed to a full range of human diversity. Particularly children with special educational needs are not discussed in detail. Similarly, specialized methods of instruction are not introduced and practiced during teacher training. It is not, therefore, surprising that these children are alien to regular school teachers. Such instance is frequently observed that during the placement of children with special needs the recipient teachers were very upset and behaved as if they have strangers in their class (Sharma et al., 2015).

The resistance to inclusive education has a strong relationship with teachers' knowledge about inclusive education (Sharma, Forlin, Deppeler \& Yang, 2013). The more recipient teachers are aware of inclusion the more they show the welcoming attitude towards children with special needs (Sharma \& Chow, 2008). During the orientation and training of regular school teachers' major deficiencies reported include lack of knowledge about disabilities and other special needs, psychology of disability, preparation and implementation of IEP, management of special needs children, transition services and adaptation in the curriculum, instruction and assessment (Sharma et al., 2013). The special education teachers are better prepared in all aspects mentioned above.

Teacher autonomy is another important aspect that creates different kinds of working environment. In general education, the teacher is thought of a functionary whose job is to do as recipe asks for doing. Under a positivistic 
paradigm, they are not supposed to use their intelligence to create knowledge. Instead, they use standard content, presented in a standard way, follow already prepared lesson plans by the expert and be accountable what he/she does (Sharma et al., 2015). A value system borrowed from a technological system based upon efficiency, standardization, total quality control, and stringent accountability is implemented in letter and spirit. It leaves no room to create and apply knowledge that is interactively produced in the classroom. Such a system is very insensitive to individual needs of the learners. The teacher is not allowed to alter classroom delivery in order to accommodate special educational needs.

In contrast, a special education teacher is exposed to various views about education such as positivistic, interpretative and critical views and hence better equipped to respond to the situation (Sharma \& Chow, 2008). These teachers have in-depth knowledge of disabilities, special teaching methods, and classroom management technique. They also know when and where the help of para-professionals is needed and how much help is acquired. A special education teacher is trained to make appropriate adaptations in special curriculum, instruction, and assessment in order to accommodate the diversified needs of learners. They are also prepared to seek school community collaboration (Sharma et al., 2015).

Students' assessment and interpretation is another important area that substantially divides the culture of special and general education. General education is now dominated by standardized testing and norm-referenced interpretation of the test data. It has transformed students' assessment into high stake testing. The consequence of these mega assessment systems is under investigation these days. Early signs are not very positive that may call for a major review (Shaukat $\&$ Rasheed, 2015). Such an inflexibility that sees every student similar to other students cannot accommodate human diversity. This assessment system must change if the goal of education today is "Education for All and No Child Left Behind" as about one-third of out of school children in Pakistan are with some kind of disability or special need (UNESCO, 2014).

The comparison outlined above in the light of Index for Inclusion (2002) indicates that the regular school is not always welcoming and equipped to accommodate all kinds of children. These schools often lack a developed culture of inclusion, the appropriate policies and guidelines, and the relevant practices necessary for the supporting student diversity. Challenges always bring opportunities but one has to out of the box in order to tap these opportunities. Based on the literature previously covered in this paper, suggestions that support the development of inclusive education will be divided into five parts; first, for the ongoing PIEP; two for improvement of infrastructure; third, for realigning the pre-service and in-service teacher education programs; fourth, for adaptation of curriculum and instruction; fifth for Quality control. 


\subsection{Ongoing PIEP}

The Punjab Inclusive Education Project is in operation in two large but educationally disadvantaged districts; namely District Muzaffargarh, and District Bahawalpur. District Bahawalpur has a total number of 1949 of institutions. Out of these 237 are located in urban areas and the remaining 1712 are in Rural Areas.

The total enrolment for the district is 247057. Urban areas have an enrolment of 63222, whereas the rural area share is 183835 . The total number of teachers is 9949, of these 2736 are teaching in urban area Institutions and 7213 are teaching in rural areas (See table 2). The number of primary schools is 1524 with 7242 teachers in which $7.6 \%$ are female. Survival rate to class 5 is $40 \%$ with pupil-teacher ratio 29 . Primary school enrolment is $1,54,712$ (NEMIS, 2012-13).

Table 2

PIEP schools in District Muzaffargarh and District Bahawalpur.

\begin{tabular}{lccc}
\hline \multicolumn{1}{c}{ District } & No. of Institutes & No. of Teachers & No. of Students \\
\hline Bahawalpur & & & \\
& & & \\
Urban & 237 & 2736 & 63222 \\
Rural & 1712 & 7213 & 183835 \\
Total & $\mathbf{1 9 4 9}$ & $\mathbf{9 9 4 9}$ & $\mathbf{2 4 7 0 5 7}$ \\
Muzaffargarh & & & \\
Urban & 141 & 1949 & 52841 \\
Rural & 2041 & 7375 & 340455 \\
Total & $\mathbf{2 1 8 2}$ & $\mathbf{9 3 2 4}$ & $\mathbf{3 9 3 2 9 6}$ \\
\hline
\end{tabular}

Source: Namis 2012-13

District Muzaffargarh has a total number of 2182 Institutions. Out of these 141 are located in urban areas and the remaining 2041 are in rural areas. The total enrolment of the district is 393296. Urban areas have an enrolment of 52841 , whereas the rural area share is 340455 . The total number of teachers is 9324, of these 1949 are teaching in an urban area and 7375 are teaching in rural areas. The number of primary schools is 1823 with 4346 teachers in which $47.6 \%$ are female. Survival rate to class 5 is $36 \%$ with pupil-teacher ratio 56. Primary school enrolment is 20306 students (NEMIS, 2012-13).

The current population of Muzaffargarh is 3.826 of that at least 28,695 are children with disabilities. This comes to 15 children with disabilities per primary school. The population of Bahawalpur is 1.052 million comprising at least 7890 children with disabilities, which means that only 5 children need to be accommodated in each primary school. This statistics may be underreported as international organizations report substantially high figures. The immediate challenge is to retrain 9949 teachers in Bahawalpur district and 
9324 primary school teachers in Muzaffargarh (Google, 2014). In both districts the implementation of the project is in progress. The willingness to include children with disabilities has not reached the level that is essential for the smooth running of inclusion. Following steps can be taken to boost the process:

For the pilot phase, an incentive to cooperating regular teachers may motivate them to new knowledge, attitudes, and methods required for the implementation. This may create ownership to carry the extra burden.

- Efforts could be made to include children in nearby school instead of gathering for a particular school.

- The community could be organized to collaborate to support inclusive education.

- It is recommended that cooperating teachers go through longterm training for learning technical details of the task.

- Teachers should be empowered to do adaptations in curriculum content and presentation modes.

\subsection{Improvement of Infrastructure}

The infrastructure of regular school needs immediate modifications in order to make it welcoming for all (Booth \& Ainscow, 2002). The most problematic infrastructure is found in urban areas where multi-storey buildings, lack of ramps, narrow paths, door, and toilets are very common. Comparatively in rural areas, structural barriers are at a minimal level, however, waterways and drain lines need bridges and coverings. The access for wheelchairs may also be a problem without sealed pavement. In order to improve these structural barriers, the government of Punjab must take emergency measures to make school infrastructure meeting international standards for inclusion. Although an emergency has been declared by the government for admission of all out of school children, during the last decade outcomes of this emergency declarations have yet to make a meaningful difference.

\subsection{Realigning the pre-service and in-service teacher education programs}

One of the major barriers to the inclusion of children with disabilities in schools is the current pre-service and in-service teacher training model in Pakistan. This is a similar issue to those in other developing countries (Sharma, 2013). According to research, one of the largest barriers is teacher attitudes (Sharma, 2012). There are multiple factors affecting teachers' attitudes which include suitable professional development opportunities and a lack of disability training in mainstream teacher training programs (Hameed \& Manzoor, 2014; Sharma et al., 2013; Bindal \& Sharma, 2010). 
The curricula for both regular teaching programs and special education teaching programs promote segregation. However, in the last few years some courses on inclusive education have been introduced in special education teacher training programs but again the addition of these courses is neither commonplace nor consistent enough to be effectively meet the needs of inclusion. In recent years, the Directorate of Staff Development has started some training courses for in-service general education teachers but only a few teachers translate these training into a practical situation (David \& Kuyini, 2002). Resultantly, these training programs remain incapable to cultivate attitude to accept children with disabilities as a regular part of the education system. Even in-service teachers training program offered under the umbrella of PIEP is initiated as a pilot project without follow up and practical evaluation. According to Sharma and Das (2015), these types of nontechnical and unsupported training programs prepare a teacher for exclusion not for inclusion.

Therefore, there is a dire need for substantial revamping to align preservice and in-service teachers training programs to make the pathway the same towards education for all children. These substantial changes are needed in pedagogical, sociological and philosophical foundations in curricula of both (general \& special) teachers training programs. Universities and higher education institutes must take a lead and focus on the increasing demand for training in inclusive education. A new degree program with the title of Degree "Inclusive Education" may be introduced to align with the emerging trend of inclusive education. Curricula of this degree program may be designed on foundations that can better produce teachers who will accept and accommodate human diversity in their classrooms.

\subsection{Adaptation of Curriculum and Instruction}

Special education programs for regular schools are developed to deliver national curriculum in Pakistan following its basic parameters for accountability and standardized testing. There is little room for classroom teachers to adapt curriculum, instruction or assessment procedures in order to accommodate the special needs of the children; therefore the curriculum remains inflexible. On the contrary, the teacher education program in special education includes courses on curriculum and instructional adaptation and multi-normed assessment procedures suiting the special needs of the children. This segregation creates a mindset that becomes a barrier to accept children with special needs in regular classrooms (Hameed \& Fazil, 2012; Manzoor, 2015).

Since, the textbooks and other instructional material in general education are not appropriate for the special educational needs of the children, resultantly, the teacher remains adamant and the parents threatened to send their children in a rigid and inflexible environment. Inclusion is a process that 
encourages individuals with a wide range of abilities to engage together in meaningful participation in an environment that fosters a sense of belongingness and autonomy (Arbour-Nicitopoulos, Grassman, Orr, McPherson, Faulkner \& Wright, 2018), therefore, it is important that such a set of activities should be developed which emphasize common goals and interests of all children. Such activities should be developmentally appropriate, and mastery-oriented individualized instruction and cooperative activities. That is why there is a need of iterant teacher for the smooth transition to inclusion.

Subsequently, to claim such teachers from the indigenous system, the preservice teacher education program could be rebuilt to align with new demands of the profession and society in general. The in-service teacher education program could plan training workshops or include a mandatory course of inclusive education in all teacher education degree programs. If timely changes are not made in order to make up this deficiency the gaps will persist in the system leading to systematic marginalization of the children with disability. The rigid array of these circumstances produces the two cultures creating a sharp divide of ability and disability.

\subsection{Quality Control}

The environment of general education is filled with slogans like benchmarking, standardization, total quality control, high scores etc. Consequently, the system exerts tremendous pressure on children to continuously remain out performers with zero failure. In such a tense academic environment, the inclusion of children with disabilities in Pakistan has become an extremely threatening initiative. It has been observed that often regular teachers do not take ownership of children with special needs. The low motivation of recipient teachers ultimately becomes barriers to inclusive education (Mehmood et al., 2018). A two-pronged strategy could be applied to transform the educational environment of regular schools into a welcoming and friendly environment. First, the knowledge of regular school teachers about inclusive education can be enhanced through refresher courses and by sharing documentaries of successful inclusion around the globe. Second, special professional training modules with sufficient back up of instructional material and assistive technology should be provided.

\section{Conclusions}

Following conclusions are drawn from the above discussion:

1. The systems of general education and special education differ from each other on aims of education, curriculum, content, pedagogy, and school assessment procedures.

2. The social, psychological and educational environment created by both systems deviates markedly. 
3. The social milieu of general education works like a sieve that segregates children on the basis of caste, color, creed, social status, and disability. It's neither welcoming nor friendly for all children.

4. The regular schools stand alone in the community and hence failed to utilize community resources for school development.

5. The dream of education for all cannot come true unless the culture of general education is transformed into a miniature inclusive society.

6. The special education system also segregates children without disability by not excepting them to be educated.

\section{Recommendations}

Following recommendations are made in the light of conclusions drawn:

The Sustainable Development Goal four aims at ensuring inclusive, free and equitable quality education, and Pakistan is signatory of the charter; therefore, government of Pakistan and especially Punjab must not let any stone unturned to initiate inclusion in public schools, especially in rural and marginalized areas.

Based on the study's findings, it is recommended that the government should review its national budget in the education sector, to consider students with special education needs in inclusive education settings. Inclusive education is a need and not a luxury; therefore all government policies and actions must be geared towards increasing inclusion at all levels.

The teachers in general public schools must be capacitated and empowered to accommodate the diversified needs of all children by adapting curriculum, instruction and assessment procedures. Teacher education programs must equip future teachers to manage inclusive environment in schools; therefore, they must be oriented toward meaningful school community collaboration in order to transform the community, which is supportive and participative for inclusive schools development.

Inclusive education is designed to enhance participation of children with disability; the activities designed must ensure every child's physical and social participation at some level, focused on enhancing competence, and selfefficacy of the children (Imms, Adair, Keen, Ullenhag, Rosenbaum, \& Granlund, 2016).

\section{References}

Alif Ailaan. (2017). Alif Ailaan Pakistan District Education Rankings 2017. Islamabad: Author.

Arbour, K. P. N., Grassman, V., Orr, K., McPherson, A., Faulkner, G. E., \& Wright, F.V. (2018). A scoping review of inclusive out-of-school time physical activity programs for children and youth with physical disabilities. Adapted Physical Activity Quarterly, 35(1), 111-138. 
ASER. (2015). Annual status of education report of Pakistan. Lahore: Idra-eTaleem-o-Aaghai.

Bakhshi, P., Babulal, G. M., \& Jean, T.-F. (2018). Education and disability in a conflict affected context: Are children with disabilities less likely to learn and be protected in Darfur? World Development, 106, 248-259.

Bindal, S., \& Sharma, S. (2010). Inclusive education in Indian context. Journal of Indian Education, 35(4), 34-45.

Booth, T., \& Ainscow, M. (2002). Index for inclusion: Developing learning and participation in schools. Bristol, UK: Centre for Studies on Inclusive Education (CSIE).

Bornstein, M. (Ed.). (1995). Handbook of parenting (1-4). Mahwah, NJ: Lawrence Erlbaum.

Bray, M., \& Thomas, R. M. (1995). Levels of comparison in educational studies: Different insights from different literatures and the value of multilevel analyses. Harvard Educational Review, 65(3), 472-491.

Carrington, S. (1999). Inclusion needs a different school culture. International Journal of Inclusive Education, 3(3), 257-268.

Croll, P., \& Moses, D. (2000). Ideologies and utopias: Education professionals' views of inclusion.European Journal of Special Needs Education, 15(1), 1-12.

David, R., \& Kuyini, A. B. (2012). Social inclusion: Teachers as facilitators in peer acceptance of students with disabilities in regular classrooms in Tamil Nadu, India. International Journal of Special Education, 27(2), 157-168.

Farooq, M. (2013). An inclusive schooling model for the prevention of dropout in primary schools in Pakistan. Bulletin of Education and Research, 35, 47-74.

Google, Map Data. (2014). District Bahawalpur. Retrieved on 26-06-17 from https://www.google.com/?client=safari\&channel=mac_bm\#safe=off \&channel

Guralnick, M. J. (Ed.). (1997). The effectiveness of early intervention. Baltimore: Brookes.

Haider, S. I. (2008). Pakistani teachers' attitudes towards inclusion of students with special educational needs. Pakistan Journal of Medical Sciences, 24(4), 632-6.

Hameed, A. (2005). Removing barriers to inclusive education in Pakistan. Paper presented at the Second Regional Seminar on Childhood Disability, Dhaka, Bangladesh. 
Hameed, A. \& Fazil, H. (2011). Implications of UN convention on the rights of persons with disabilities 2007 for education policy in Pakistan. Paper presented at the International Conference on EDULEARN1 (pp. 584-589). Barcelona, Spain.

Hameed, A. \& Fazil, H. (2012). Sustainable quality education for the children with disabilities in Pakistan. SAARC Journal of Educational Research, 9, 14-24.

Hameed, A. \& Manzoor, A. (2014). Making children visible as right bearers for education. In A. Husain, A. Masih, I. Husain \& H. K. Bhatia (Eds.), Education as a right across the levels: Challenges, opportunities and strategies (pp. 395-401). New Delhi: Viva Books.

Manzoor, A., Hameed, A., \& Nabeel, T. (2018). Analysis of parents voices about the educational exclusion of children with disabilities. Journal of Inclusive Education, 2(1), 77-92.

Imms, C., Adair, B., Keen, D., Ullenhag, A., Rosenbaum, P., \& Granlund, M. (2016). Participation a systematic review of language, definitions and constructs used in intervention research with children with disabilities. Developmental Medicine \& Child Neurology, 58, 29-38.

Latif, A., Choudhary, A. I., \& Hammayun, A. A. (2015). Economic effects of student dropouts: A comparative study. Journal of Global Economics, $3,137$.

Manzoor, A. (2015). Analysis of being unreached and its compatibility with available educational provisions (Unpublished M. Phil Thesis). Allama Iqbal Open University, Islamabad.

Mehmood, S., Chong, L., \& Hussain, M. (2018). Female higher education in Pakistan: An analysis of socio-economic and cultural challenges. Advances in Social Sciences Research Journal, 5(6), 379-397.

Miles, S., \& Singal, N. (2010).The education for all and inclusive education debate: Conflict, contradiction or opportunity? International Journal of Inclusive Education, 14(1), 1-15.

Mizunoya, S., Mitra, S., \& Yamasaki, I. (2018). Disability and school attendance in 15 low-and middle-income countries. World Development, 104, 388-403.

NCHD. (2010). National Commission on Human Development Report. Retrieved on 23-11-17 from http://www.nchd.org.pk

NEMIS. (n.d.). District education statistics 2012-2013. Islamabad: Academy of Educational Planning and Management, Federal Ministry of Education and Professional Training. 
Sathar, Z. A., \& Lloyd C. B. (1994). Who gets primary schooling in Pakistan: Inequalities among and within families. The Pakistan Development Review, 33(2), 103-134.

Sharma, U. (2011). Changing heart, head, and hands of teachers to teach in inclusive classrooms: Why and how? Bangladesh Education Journal, 10(2), 7-18.

Sharma, U. (2012). Changing pre-service teachers' beliefs to teach in inclusive classrooms in Victoria, Australia. Australian Journal of Teacher Education, 37. Retrieved on 30-06-17 from http://ro.ecu.edu.au/ajte/vol37/iss 10/4

Sharma, U. \& Das, A. (2015). Inclusive education in India: Past, present and future. Nasen Support for Learning, 30(1), 55-68.

Sharma, U., \& Chow, E, (2008). The attitudes of Hong Kong primary school principals toward integrated education. Asia Pacific Education Review, 9(3), 380-391.

Sharma, U., Forlin, C., Deppeler, J., \& Yang, G. (2013). Reforming teacher education for inclusion in developing countries in the Asia Pacific region. Asian Journal of Inclusive Education, 1(1), 3-16.

Sharma, U., Simi, J., \& Forlin, C. (2015). Preparedness of pre-service teachers for inclusive education in the Solomon Islands. Australian Journal of Teacher Education, 40(5), 103-116. Retrieved on 14-04-17 from http://ro.ecu.edu.au/cgi/viewcontent.cgi?ar

Shaukat, S., \& Rasheed, K. (2015). Student teachers attitudes towards inclusion in Pakistan. Bahria Journal of Professional Psychology, 14(1), 72-89. Retrieved on 13-05-17 from http://oaji.net/articles/2017/6066-1522726888.pdf

Singal, N. (2015). Education of children with disabilities in India and Pakistan: An analysis of developments since 2000 (Background paper prepared for the Education for All Global Monitoring Report 2015 Education for All 2000-2015: achievements and challenges). Cambridge: University of Cambridge.

Triano, S. (2000). Categorical eligibility for special education: The enshrinement of the medical model in disability policy. Disability Studies Quarterly, 20(4), 399-412.

UNESCO. (2006). Guide for planning education in emergencies and reconstruction: Non-formal education. Paris: Author.

UNICEF. (2013). All children in school by 2015 global initiative on out of school children. Islamabad: Author. 